\title{
O MOVIMENTO SOCIAL E A ESCOLA: DA CRIAÇÁO PASSADA À INVENÇÃO NECESSÁRIA
}

\author{
José Adelson da Cruz
}

O objetivo desse artigo é apreender os sentidos e significados das demandas pautadas pelos movimentos sociais para escola e sua materialidade nas atuais políticas e legislação educacional. Busca-se discutir as idéias de democracia, qualidade e cidadania presentes na atuaçáo de gestores, professores, técnicos administrativos, alunos e pais, com a finalidade de compreender os valores e princípios estruturantes das práticas escolares, recuperando temas emergentes no debate atual. Com as reflexões feitas, pode-se destacar como resultado alcançado que a inspiração das práticas dos movimentos sociais da década de I980 não se imprimiu suficientemente na escola que se faz hoje. $\mathrm{O}$ que se constata é que a gestão implantada ainda não transformou a escola, mas há, em contrapartida, uma participação induzida e corporativa, cujo sentido de intervenção das famílias, das organizações sociais e das empresas pauta-se pelo suprimento de "carências" inerentes à desresponsabilização do Estado para com a educação pública.

Palavras-Chave: Democracia. Gestão escolar. Movimentos sociais.

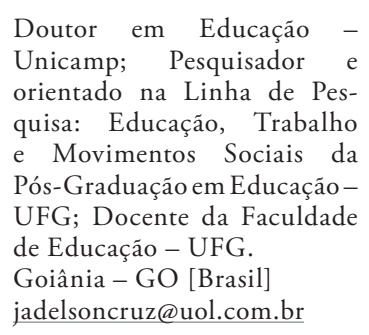




\section{$1 \quad$ Notas introdutórias}

Historicamente, a relação entre movimentos sociais e educação é norteada por elementos em comum: a questão da participaçáo, da cidadania e do sentido político da educação. Isso porque a educação ocupa lugar central na acepção de cidadania, constituída no processo de luta que é, em si mesmo, um movimento educativo no interior das práticas sociais. No âmbito escolar, por meio das exigências dos movimentos sociais, da intervenção das organizações sociais, da atuação da União dos Dirigentes Municipais de Educação (Undime), das Conferências Brasileiras de Educação, dos Sindicatos de Professores, do Fórum Nacional de Defesa da Escola Pública e das Conferências da Organização das Nações Unidas (ONU), elaborou-se uma concepção de escola voltada para as transformaçóes sociais e mobilidade social, que dê sua contribuição para a construção da democracia. Esse conceito formatou outras maneiras de organizar as práticas pedagógicas, auxiliou na implantação da nova legislação educacional e incutiu certo otimismo pela educaçáo. Constituiu-se como combustível para o avanço das lutas pela expansão da escolaridade e tornou-se o "espírito" dos anos I980.

Nesse mesmo registro, a vitória da oposição em algumas capitais abriu espaços para as participações comunitárias e a organização sindical de trabalhadores da educação. Pode-se citar como exemplos a luta por uma escola de qualidade; por creches e, depois, pela educação infantil; por eleição direta para diretores das escolas públicas, naquele momento como ato indispensável à construção de um projeto democrático de escola, à criação dos conselhos e à gestão participativa, bandeiras de luta que foram reconhecidas na Constituição Federal de 1988.

A marca maior daquele período diz respeito ao estreitamento das relaçóes entre escolas e bairros que extrapolavam as dinâmicas próprias do processo escolar. Nesse particular, as estruturas físicas das escolas estavam à disposição da "comunidade" e se constituíam em espaços para encontros, 
manifestaçôes, celebrações religiosas e atividades de lazer. Observa-se, hoje, a ausência da "comunidade" na escola como extensão de sua vida cultural, mas assisti-se, em contrapartida, a uma participação induzida e corporativa, que tem como finalidade a intervenção das famílias, das associaçôes de moradores, dos grêmios e até de emissora de televisão, pautando-se por uma concepção apolítica da educação e da participação política da sociedade.

Os movimentos sociais, com seu caráter educativo, modificaram significativamente a relação entre assistência e direitos sociais no Brasil. Para isso, instalaram valores e princípios de uma cultura política participativa, multiplicando-se por todo o País e construindo uma vasta teia de organizaçóes que se mobilizam em torno da conquista, da garantia e da ampliação de direitos, quer contra a exploração do trabalho e a especulação imobiliária, quer em oposiçáo às mais diversas formas de discriminaçáo como as de gênero e raça, estabelecendo novas relaçôes com a natureza, saúde e educação.

Assim, o caráter educativo dos movimentos sociais apresenta-se como forma de aprendizagem aos participantes das mobilizaçôes, das organizaçôes e dos movimentos em geral, como efeito pedagógico multiplicador, capaz de organizar e sistematizar saberes, demandas e bandeiras de lutas, a exemplo das eleiçôes diretas para diretores, projeto político-pedagógico e gestão democrática da escola. Esse conjunto de atividades, de procedimentos e de mecanismos das lutas no campo da educação introduziu, na escola, questôes que dizem respeito ao acesso, permanência e qualidade social da educação contemporânea.

Desde o início da década de 1990, a gestão democrática passou a ser um tema muito presente na educação, margeando, especialmente, os campos ligados às políticas educacionais e à legislação educacional. É esse percurso que nossa reflexão busca apreender: a relação entre as demandas pautadas pelos movimentos sociais para escola e suas materialidade nas políticas e legislaçáo educacional, com o intuito de apontar e discutir as ideias de democracia, de qualidade e cidadania predominantes na atuaçáo de ges- 
tores, professores, técnicos administrativos, alunos e pais, e indagar sobre os valores e princípios estruturantes das práticas escolares para compreender o hoje, recuperando temas emergentes no debate atual.

\section{O movimento social e os desafios históricos}

É amplamente reconhecido que as últimas quatro décadas marcaram uma ruptura significativa com a ordem social, política, econômica e cultural que caracterizou os decênios que se seguiram à Segunda Guerra Mundial. Ocorreram mudanças básicas como o enfraquecimento e a transformação dos estados de bem-estar social do capitalismo ocidental, o colapso do socialismo real do Leste Europeu e o solapamento do Estado desenvolvimentista. De modo geral, as décadas recentes viram o enfraquecimento da soberania econômica estatal nacional e a emergência e consolidação da ordem global neoliberal. Assim, a vida social, política e cultural tornou-se cada vez mais descentrada e fragmentada.

Para Jameson (2004), a sociedade capitalista em sua forma contemporânea se caracteriza pela fragmentação de todas as esferas da vida social, da produção, da dispersão espacial e temporal do trabalho, do desemprego estrutural e da destruiçáo das referências que balizam a identidade de classe e das formas da luta de classe. A sociedade "aparece" como uma rede móvel, instável e efêmera de organizaçôes particulares definidas por estratégias particulares e programas competindo entre si, que deve ser gerida, programada, planejada e controlada por estratégias de intervenção tecnológica e jogos de poder.

Essas mudanças ocorreram no contexto de um longo período de estagnação e crise. No entanto, esses fenômenos da crise não levaram ao ressurgimento dos movimentos da classe trabalhadora. Ao contrário, as décadas passadas assistiram ao declínio dos clássicos movimentos de trabalhadores e à 
emergência de novas ações coletivas, frequentemente caracterizadas por políticas de identidade, incluindo movimentos ambientalistas, relacionados à livre orientação sexual e às várias formas de "inclusão" e controle social. Indagar sobre as transformaçóes, então, requer levar em consideração não apenas o declínio econômico de longo prazo, ocorrido desde o início da década de I970, mas também mudanças importantes na vida social e cultural.

$\mathrm{Na}$ academia, atualmente, há uma tendência crescente de desqualificar e mesmo ignorar trabalhos realizados há mais de 20 anos - o caso dos movimentos sociais, que parecem não encontrar espaço de diálogo em uma nova agenda de prioridades. Aparentemente, essa postura justificar-se-ia pelas transformações sociais tão singulares e radicais, que somente uma nova abordagem teórica poderia dar conta do observado. O interesse, por meio deste artigo, é tratar da relação entre movimentos sociais e escola, é ir ao encontro dessa postura, pois concentra-se no resgate de questionamentos formulados durante a década de I980, com pertinência e desdobramentos importantes hoje, como o caso das açôes coletivas. Ainda que privilegiando a importância de considerar movimentos, processos e transformações históricas, acredita-se que haja questôes de períodos históricos distintos cujas proposiçôes centrais tenham tradução e relevância em nosso tempo.

Os movimentos sociais constituem um tema que só nos anos 1980 ganhou maior envergadura de pesquisa, sem que tenha deixado de ser extremamente polêmico, do ponto de vista interpretativo. Nele estão embutidas questôes teóricas extremamente complexas, entre as quais o caráter das lutas desenvolvidas e sua relação com a classe; suas (des)articulações com partidos políticos ou seus antagonismos em relação ao Estado. Hoje, estudos questionam seu significado cultural no que se refere a gerar novas formas de sociabilidade e valores que se contraponham ao clientelismo, tão marcadamente presente na sociedade brasileira, ou ainda, seu significado político no atual contexto. Sabe-se que tais trabalhos apontam as organizações não governamentais (ONGs), como fase evoluída dos movimentos. Finalmente, 
além da questão da extensão da cidadania, em razão das contradiçóes inerentes ao processo de globalização de mercados e de apropriação de riquezas altamente excludente, tematizam acerca do potencial de radicalidade das lutas sociais, cujo horizonte náo se esgotaria nos parâmetros de uma sociedade capitalista.

As organizações multilaterais espraiam a idéia de "educação permanente ou continuada". Advogam que, diante de um mundo globalizado e em transformação constante, a educação permanente ou continuada é uma estratégia pedagógica indispensável, pois somente com ela é possível adaptar-se às mudanças incessantes no mercado de trabalho. Nessa nova concepção, a educação não se confunde com os anos escolares e a profissão, isto é, deixa de ser preparação para a vida e para o trabalho e torna-se capacitação de leigos para atividades transitórias durante toda a vida.

Para Castel (200I), a ideia de "educação permanente ou continuada" confunde educação com "reciclagem". Trata-se de aquisiçôes de técnicas por meio de processos de adestramento e treinamento para saber empregá-las de acordo com as finalidades das empresas. Tanto é que muitas organizaçóes empresariais possuem escolas, centros de treinamento e reciclagem para atender seus empregados, ou fazem convênios com outras empresas destinadas exclusivamente a esse tipo de atividade.

Outra novidade é a reatualização da ideia de Identidade que, de acordo com teorias marxistas, weberianas ou durkheimianas, era a identidade de um grupo de acordo com o posicionamento de seus membros em relação ao antagonismo entre capital e trabalho, com a renda e status adquiridos, ou de acordo com representaçóes coletivas socialmente consolidadas. Conceitos tradicionais das ciências sociais, no entanto, tornaramse insuficientes para explicar a pluralidade de novos movimentos sociais, dos desafios postos às identidades com que, até então, eram associados e da diversidade de questóes que levantam na legitimação de suas reivindicações (SANTOS, 2003). 
Sabe-se que tudo isso respira os ares desses tempos de neoliberalismo "vitorioso", traduz o que Telles (200I) e Oliveira (1999) chamam de "ambiência social conservadora", na qual as mudanças em curso estão sendo conduzidas e reatualizam uma pesada tradição de desigualdades e exclusóes. Trata-se de uma ação política que expressa e, ao mesmo tempo, duplica processos muito excludentes que correm por fora do poder de interpelação de sindicatos, partidos, associaçóes de classe e movimentos sociais. Essa é a recente democracia brasileira: "[...] uma sociedade civil restrita ou truncada, na qual as práticas de representação e negociação se generalizam com dificuldades para além dos grupos mais organizados" (TELLES, 200I, p. I20). Tal procedimento joga organizados e desorganizados a sua própria sorte, pelo fato de não serem medidos as necessidades e os interesses que possam ser formulados nos termos dos direitos, tornando factível a representação.

Desde os anos 1980, Wanderley Guilherme dos Santos (1993) define essa situação como "confinamento regulatório da cidadania". Não se trata de uma sociedade dividida entre "organizados" e "não organizados", mas de algo que se instaura no interior da sociedade organizada, por conta do modo como o legal e o institucional se organizam.

Abordar os aspectos políticos implicados na relaçáo educação e cidadania, resgatar as relaçôes, por vezes difíceis, de alguns movimentos sociais e organizaçóes não governamentais com a democracia ajuda-nos a formular, de maneira mais pertinente, o problema das práticas educativas recentes, pois a contemporaneidade é caracterizada pela "[...]formação de um padrão especificamente periférico de cidadania e subcidadania [...]" (SOUZA, 2006, p. I53) que, no entender de Souza, "[...]é fruto do novo período que instaura um novo padrão de intitucionalidades[...]" (2006, p. I53). Com isso, desde já evitamos a armadilha de transformar a escola em panaceia para questóes como a da inclusão social ou aquelas ligadas à participação política.

Nosso tempo é marcado pela aparente "desnecessidade do público", cuja razáo de ser - como assinala a atual açấo dos governos da Comunidade 
Europeia e dos Estados Unidos em estatizar e nacionalizar bancos, imobiliárias e seguradoras - evidencia a publicização dos custos e prejuízos e a privatização dos lucros, contraditoriamente, ganha corpo e forma a noção de "mobilização social", como um instrumento, uma ferramenta para "convocar vontades" de cidadãos, de organizaçóes sociais, de empresas e do Estado por intermédio dos programas sociais focalizados. A mobilização social, nesse momento, consiste no envolvimento ativo do voluntário, da organização social, da empresa e do governo nos rumos e acontecimentos da sociedade.

E isso muda tudo no que diz respeito à questão social, pois, nas atuais políticas a exclusão, é deslocada, na opinião pública, do lugar em que é politicamente construída, isto é, o entendimento da exclusão/inclusão como inerente ao capital passa para o lugar da não política, figurando a exclusão como dado a ser administrado tecnicamente ou gerido pelas práticas de filantropia. Nesses termos, ao entender a política como puro campo da gestão, dos procedimentos e da regularidade institucional, perde-se de vista a discussão sobre seus propósitos e a possibilidade de intervenção sobre eles. Observa-se uma laboriosa construção do esquecimento da própria origem da política, como se ela viesse de nenhum lugar e fosse destituída de qualquer fundamento. "O esquecimento da política é a privatização da vida - o esquecimento da coisa pública em proveito do privado - é o preço que se paga com a progressiva destruição do espaço público e da dimensão pública das instituições" (ARENDT, 200I).

Dessa forma, a sociedade civil, em sua heterogeneidade organizacional, perdeu o sentido e o campo de crítica e emerge apenas como cooperação em que cabe todo tipo de associaçóes civis, entendidas como organizaçóes privadas para a ação pública. Com efeito, tal metamorfose efetiva a despolitização das relaçóes entre a sociedade e o Estado, pois o conflito desaparece da cena pública. Nota-se que as restriçóes à democracia participativa não decorrem apenas dos limites interpostos à participação política, mas, em grande parte, pela redução dos temas de deliberação na cena pública. A participação 
política é confundida com o consenso e a política deixa de ser "[...] a reivindicação da parte dos que não tem parte a uma intervenção de expedientes" (RANCIÈRE, I996).

Tomando o cuidado de não considerar universais fatores históricos, é possível usar o fato de que a simples afirmação do princípio da igualdade entre os indivíduos não é suficiente para produzir as condiçóes necessárias para uma vida democrática plena. Assim, um primeiro aspecto que se deve reter sobre a cidadania é o de que ela depende de sua existência concreta no tocante aos meios essenciais à produção e à reprodução da vida para que possa ser um fator determinante nos destinos da vida democrática. Nesse sentido, não há cidadania sem a correspondente afirmaçâo das oportunidades iguais para uma vida digna.

Entre as açôes coletivas contemporâneas, os movimentos sociais diferenciam-se de um grupo de pressão, de um movimento de ideias ou de reivindicaçôes pelos tipos de princípios que os orientam, isso porque o movimento social põe em questão uma forma de dominação social particular ou geral e invoca com ela valores e orientaçóes gerais para a sociedade. Dessa forma, sua presença ou ausência na cena política determina quase todas as formas de açôes coletivas. Só é movimento social se sua atuação causar um impacto maior do que a simples defesa dos interesses particulares, pois seu caráter educativo formata energias utópicas.

A atual configuração da política neoliberal tem apresentado desafios à expansão da cidadania e da democratização da sociedade, especialmente na urgente necessidade de romper com o fatalismo econômico não só no discurso midiático-político, mas também pelo próprio comportamento de governos na flexibilização de direitos sociais. Bourdieu (200I) aponta como um grande passo à construçáo de alternativas a esse estado de coisas a ruptura com um tipo de pensamento que tende a desacreditá-lo e, com a açáo crítica, passa a valorizar o consenso social que, no limite, divide com a sociedade civil uma política de responsabilizar os miseráveis por sua própria sorte. Para o autor, 
[...] a história social ensina que não existe política social sem um movimento social capaz de impô-la, e que não é o mercado, como se tenta convencer hoje em dia, mas sim o movimento social que "civilizou" a economia de mercado, contribuindo ao mesmo tempo enormemente para sua eficiência.

[Os movimentos sociais] criam ou recriam formas de ação originais, em seus fins e seus meios, de forte conteúdo simbólico. Orientam-se para objetivos precisos, concretos e importantes para vida social [...] Exaltam a solidariedade, que é o principio tácito da maioria de suas lutas, além de se esforçarem para exercê-la tanto por sua ação (encarregando-se de todos os "sem-") como pela forma de organização de que são dotados. (BOURDIEU, 200I, p. 19-65, grifos do autor).

Ora, a contribuição dos movimentos sociais para a democratização certamente não é só aquela que cabe a organizaçóes como sindicatos ou partidos políticos, porque as inovaçóes dos movimentos sociais residem precisamente em seu "enraizamento" nas esferas sociais. E é nas esferas da vida social e na sua articulação com a política que os movimentos sociais estabelecem, como arenas institucionais que podem emergir, os impulsos mais promissores para a construção da democracia. Hoje, pode-se destacar, como resultado alcançado, que a inspiração das práticas e as representações simbólicas e políticas dos movimentos sociais da década de I980, de base comunitária, não se imprimiram suficientemente na consolidação da democracia.

Assim, os movimentos sociais têm de se apresentar como representantes típicos de determinados valores, como inovadores culturais capazes de criar novas normas e instituiçóes que permitam canalizar recursos de uma maneira diferente. $\mathrm{O}$ poder desses movimentos náo depende tanto dos dirigentes da organização e das redes de troca, mas do compromisso subjetivo com a lealdade e a solidariedade. Esses compromissos só podem ser estabelecidos quando 
os movimentos criam e sustentam novos significados e novas identidades pessoais e grupais mais atraentes. São ações de natureza prática e histórica que só obtêm êxito se forem capazes de empregar a linguagem civil para relacionar seus problemas práticos ao centro simbólico da sociedade e às suas premissas utópicas universalistas.

\section{A escola e a invenção necessária}

No que se refere à escola, já a partir de I980, alguns estudos sobre os movimentos sociais começaram a relacionar a questáo da educação a esses movimentos para identificar, em suas lutas, a preocupação com a escola, preferencialmente nas periferias urbanas (SPÓSITO, I984). Para Gohn (I992), esses estudos, porém, não chegaram a envolver a reflexão sobre a dimensão educativa dos movimentos. De modo geral, predomina até hoje a polarização que se transformou em marca do pensamento educacional: ou se trata da educação somente por meio da escola, ou não se entra nessa discussão.

Embora a escola e os movimentos sociais eduquem, o que têm em comum é o sentido político da educação. Cabe, portanto, ressaltar o caráter educativo manifesto nessas experiências, assim como constatar os espaços das práticas sociais como lugares adequados ao desenvolvimento de uma educação crítica e emancipatória, isto é, os movimentos sociais devem ser vistos como espaços educativos, no sentido amplo do termo. Trata-se da produção de um "saber social" ou "[...] um saber socialmente determinado [...]”, nos termos de Cândido Grzybolwki (I986, p. 50), que se aprende e se ensina nos movimentos sociais, portanto, em estreita relação com a cultura política.

Nesse sentido, o movimento social é, ao mesmo tempo, um conflito social e um projeto cultural articulado por força de interesses e necessidades que permitem a emergência de sujeitos sociais coletivos, isso porque os 
movimentos sociais podem ser considerados como índices da democracia real, ou como potência dela, para viabilizar o quadro das liberdades e da humanização dos homens, à medida que modificam as relaçôes sociais e, portanto, as de poder nas suas várias formas.

Desde os anos I990, no cenário neoliberal - marcado pela desconstrução de direitos e por políticas assistenciais focalizadas e compensatórias -, criou-se uma linguagem que acabou por se impor ao conjunto da sociedade, gerando um campo de indeterminaçóes, uma zona cinzenta, em que apreender termos como Identidade, democracia e cidadania, para dizer o menos, tornou-se bastante difícil e complexo. Os novos discursos assumidos por empresas e pelo Estado aproximam essas instituições do léxico dos movimentos sociais e das organizaçóes civis, de tal forma que, muitas vezes, suas "funções" se confundem.

Dessa forma, a linguagem corrente obscurece diferenças, dilui matrizes e reduz antagonismos. Esse processo se materializa no encolhimento do espaço público e no alongamento do espaço privado sob os imperativos da nova forma de acumulação do capital, conhecida como neoliberalismo. Uma das consequências dessa situação é a transformação de direitos econômicos e sociais em serviços definidos pela lógica de mercado e pela transformação do cidadão em consumidor.

Rey (2007) constata que os discursos e práticas políticas se estruturam do mote "crer e fazer crer" que, ao dar à política consistência e, ao mesmo tempo, fragilidade, constitui um paradoxo. Assim, o poder utiliza a palavra para dominar, mas, para isso, necessita destituí-la de seu sentido originário. Em um primeiro momento, o poder busca o esquecimento das operaçóes pelas quais uma palavra se constitui, introduzindo, de forma velada, outros valores. Dessa forma, a força da palavra substitui a da coisa, da ideia, do fato; e quanto mais realidade falta à coisa, mais a palavra é necessária para compensar o "reino da violência artificial". Assim ocorre com a ideia "gestão democrática da educação". 
A noção de Gestão Democrática representa um veio privilegiado para a discussão de um dos maiores impasses enfrentados pelos educadores: a participação e a qualidade social da escola, materializadas na repetência e evasão escolar. Isso porque a educação é uma prática social constituída na estreita relaçáo com o conjunto das ciências sociais e com outras áreas do conhecimento. Descobrir-se no seio dessa contradição e em seus desdobramentos e, ainda, apreender a tensão que lhe é inerente são condiçôes de todos aqueles que pensam a educação e nela atuam, seja ela entendida em sua dimensão mais particular, que é a escolar, ou mais global, a cultura.

A questáo de fundo, quando pensamos em movimentos sociais e educação, é a relação escola e espaço público como lugar e modo específicos de agir que condense a cidadania e a democracia, em que entra em jogo o que aparentemente há de mais trivial - a sociabilidade cotidiana -, mas por um ângulo muito especial, ou seja, em uma forma particular, com capacidade para relacionar-se com o outro de maneira inteira e com inteiro respeito. $\mathrm{Ou}$ seja, aponta para um conjunto de práticas que não se encaixa bem na visão de que a gestão da escola é uma atividade especializada, uma atividade de "peritos", de dirigentes, o que faz a açấo política deixar de ser um problema de sujeitos coletivos.

$\mathrm{Na}$ contramão dessa tendência, visando apreender a institucionalização dos mecanismos de participação indicados pela atual legislação no "chão" da escola, é necessário assinalar a questão do vínculo entre associaçôes de caráter local e sua transformaçáo em canais de expressão de interesses e de carências e as dimensóes universalizantes que dizem respeito à consolidação dos espaços públicos e à superação das desigualdades e das carências pela consolidação dos direitos sociais.

O artigo I 4 da Lei de Diretrizes e Bases da Educação Nacional (Lei $\mathrm{n}^{\circ}$ 9.394, de 20 de dezembro de 1996) (LDB) assinala os princípios sobre os quais a ideia de Gestão Democrática minimamente se edificará: "Iparticipação dos profissionais da educação na elaboração do projeto peda- 
gógico da escola; II- participação das comunidades escolar e local em conselhos escolares ou equivalentes”. Esse parece ser o patamar mínimo sobre o qual o discurso de democratização da gestão e, por consequência, da educação consubstanciou-se País afora. Assim, a legislação deliberou uma infinidade de mecanismos voltados para tais propósitos. A título ilustrativo, vejamos: Conferência da Educação, Conselho Municipal da Educação, Conselho de Acompanhamento e Controle Social do Fundo Nacional de Manutenção e Desenvolvimento da Educação Básica (Fundeb), Orçamento Participativo na Educação, Projeto Político Pedagógico, Eleições de Dirigentes Escolares, Conselho de Escola, Associação de Pais, Grêmio Estudantil, entre outros.

As reflexôes de diferentes autores examinados, tais como Dourado (2003) e Ferreira; Aguiar (2000), indicam, de modo explícito, as mudanças que se processaram na política e gestão da educação nos últimos anos, em decorrência das profundas transformaçóes por que passou o mundo nas últimas décadas. Consequentemente, parte significativa dos elaboradores e executores de políticas educacionais, gestores públicos, educadores e pesquisadores desenvolveram certo "consenso" da necessidade de reformas educacionais que equacionou e reduziu a gestão a uma mera questão de escolhas administrativas, e a democracia, a método e tecnologia social de participação concedida. Essa percepção não é somente privilégio do debate acadêmico sobre educação, mas do conjunto das políticas sociais, porque o significado de democracia tornou-se ambíguo, e a conveniência retórica dessa ambiguidade, mais evidente do que nunca.

A institucionalização de mecanismos que ampliem a democracia nos processos de gestão e organização da escola é fundamental. No entanto, pode significar muito pouco se os seus princípios não estiverem alicerçados à cultura democrática participativa. Certamente, tal invenção não é só um desafio da escola, pois, para superar os limites da democracia contemporânea, essa empreitada deverá ser política. Isso porque a educação é direito de todos, im- 
plicando a superação da ideologia do mérito e da competição que apenas contribuem para justificar as desigualdades no interior da escola. Por outro lado, é necessário que a escola estatal seja entendida como serviço e bem público, pois a educação é uma ação de interesse público.

A realizaçáo de eleiçóes para diretores e a implementação dos diferentes mecanismos, por si sós, náo modificaram o raciocínio de gestores, de professores, funcionários, alunos e seus familiares que reconhecem, na direção, não uma representação da comunidade escolar, mas alguém que possui o poder de decidir tudo a seu modo e, pior, não constata aí um grande problema, por entenderem que a direçáo foi eleita justamente para isso. Na prática, o que essa direção possui é um mandato imperativo, na medida em que os interesses particulares, por melhores que possam parecer, acabam representando prioridade sobre os interesses coletivos.

Desse modo, as diversas alternativas de democratização da escola que vêm sendo adotadas, esbarram por vezes, na própria institucionalizaçáo da ideia, a ponto de a forma substituir o conteúdo. Em outras palavras, a busca pela ampliação do diálogo e pela participação de todos na construção e administração da escola e da educação pública se transforma na simples organização formal de espaços de representação, que, por mais importantes que sejam, não são suficientes ao necessário avanço democrático.

$\mathrm{Na}$ acepção de Gaulejac (2007), a gestão se instaura como ideologia que legitima uma abordagem instrumental, utilitarista e contábil das relações entre homem e sociedade. "[...] Sob uma aparência pragmática e racional, a gestão subentende uma representação do mundo que justifica a guerra econômica" (2007, p. 27).

Para apreender a democratizaçāo da escola, torna-se necessário compreender que é na experiência da pluralidade e da diversidade entre as perspectivas diferentes - pode-se chegar ao entendimento e ao consenso - que o significado primeiro do espaço público pode ser encontrado no "agir em concerto". Para Arendt, "[...] o espaço público estabelece as fronteiras que 
tanto ligam quanto separam as pessoas, que tanto as une quanto as impede de tropeçar umas nas outras" (200I, p. 62).

Reconhecer isso expóe a necessidade de consolidar a escola como espaço público, fazendo com que deixe de ser tratada como continuaçáo da casa ou espaço de voluntarismo, enfim como espaço que náo pode ser privatizado, pois a "[...] perda do mundo comum, equivalente a privação de um mundo compartilhado de significaçóes [...]" (ARENDT, 200I, p. 62), decorre da eliminação da esfera pública e da diluição da distinção entre o público e o privado; e o estabelecimento da instrumentalidade e do consumo como os modos básicos de se relacionar com as coisas no mundo.

O dilema é complexo e pode ser mais bem abordado se entendermos que, dialeticamente, a democracia é um processo em construçáo, o que significa que ela inclui a possibilidade de definir - sempre de modo conflitante - os valores e as práticas que constituem sua esfera de ação.

\section{$4 \quad$ À guisa de conclusóes}

O esforço analítico desenvolvido até aqui, mais do que um diagnóstico, foi o de refletir sobre as transformaçôes e inovaçóes no repertório das lutas sociais que demarcam interesses diversos, identidades, subjetividades e diversificação dos projetos em disputa e, portanto, mudanças nas demandas, nas formas de publicizar e no formato dos movimentos sociais, ou seja, houve desdobramento e articulação de demandas tradicionais e novas. $\mathrm{O}$ fato novo é que, a partir de I990, os movimentos sociais passaram a integrar formas de organizaçóes mais institucionalizadas, como os fóruns e ONGs e participam de uma infinidade de conselhos políticos e gestores.

A democracia e a cidadania, definidas como ação política, exigem uma dimensão mais substancial e radical do que a proposta pela democracia liberal, pois o exercício da cidadania vincula-se ao reconhecimento de certas res- 
ponsabilidades derivadas de um conjunto de valores construtivos daquilo que se poderia definir como o campo da ética cidadã. Nesses termos, a cidadania é considerada uma dimensão que excede o meramente formal para associar-se, de forma indissolúvel, a um tipo de ação política e de possibilidades concretas para a realização dos atributos que a definem como "o direito a ter direito".

Desse ponto de vista, talvez se possa afirmar que as tensóes vivenciadas na comunidade escolar entre uma possível experiência de igualdade e de sua reinvenção na equidade e a possibilidade de uma gestão democrática se referem aos tempos de deslocamento e esquecimento da política. Assim, apesar de todas as esperanças que foram depositadas nos mecanismos de participação, talvez seja possível pensar essas inovaçóes como parte de um manto nebuloso de normalidade que encobre condiçóes miseráveis de vida e acaba por interditar a política e sua reinvenção para as parcelas que aparecem como descartáveis e condenadas ao isolamento e à desolação proveniente de seu encapsulamento.

Como lembra Arendt, a vida pública assume o aspecto enganoso de uma soma de interesses privados, como se esses interesses pudessem criar uma nova qualidade de vida por meio da mera adição. Tudo isso é uma ilusão, pois não difere do bem privado e é, por natureza, inclinado para o benefício privado. Contemporaneamente, as ações coletivas e as políticas sociais têm-se efetivado na direção em que há indistinção entre público e privado.

\section{THE SOCIAL MOVEMENT AND THE SCHOOL:}

\section{FROM THE PAST CREATION TO THE NECESSARY INVENTION}

This article aims to give a comprehension to the senses and the meanings of the necessities of the social movements for the school and its materiality in the current policies and educational legislation. It is 
intended to discuss ideas of democracy, citizenship and quality in the performance of managers, teachers, school employees, students and parents, as a way to understand the values and fundamental principles of school practices, bringing subjects discussed today. As a result, it is important to emphasize that the practices of social movements of the 1980s were not well established in the school nowadays. What we see is that the management implanted still has not modified the school, but, in contrast, an induced and corporative participation, which sense of involvement of families, social organizations and enterprises, is determined by the supply of "lacks" that decrease the responsibility of the State to public education.

KEY WORDs: Democracy. School management. Social movements.

\section{Referências}

ARENDT, H. A condição humana. São Paulo: Forense Universitária, 200 I.

BOURDIEU, P. Contrafogos 2: por um movimento social europeu. Rio de Janeiro: Jorge Zahar Editor, 200I.

CASTEL, R. As metamorfoses da questão social: uma crônica do salário. Petrópolis: Vozes, 200 I.

DOURADO, L. F. (Org.). Gestão escolar democrática: a perspectiva dos dirigentes escolares da rede municipal de ensino de Goiânia-GO: Goiânia: Alternativa, 2003.

FERREIRA, N. S. C.; AGUIAR, M. Â. da S. (Org.). Gestão da educação: impasses, perspectivas e compromissas. São Paulo: Cortez, 2000.

GAULEJAC, V. de. Gestão como doença social: ideologia, poder gerencialista e fragmentação social. Aparecida: Idéias \& Letras, 2007.

GOHN, M. G. Movimentos sociais e educaçâo. São Paulo: Cortez, 1992.

GRZYBOWSKI, C. Esboço de uma alternativa para pensar a educação no meio rural. Contexto e Educação, n. 4, Ijuí, Universidade Ijuí, I986. 
JAMESON, F. Pós-modernidade: a lógica cultural do capitalismo tardio. São Paulo: Ática, 2004.

OLIVEIRA, F. de. Privatização do público, destituição da fala e anulação da política: o totalitarismo liberal. In: OLIVEIRA, F.; PAOLI, M. C. Os sentidos da democracia: políticas do dissenso e hegemonia global. Petrópolis: Vozes, 1999.

RANCIÈRE, J. O desentendimento: política e filosofa. São Paulo: Editora 34, 1996.

REY, J. M. O império das palavras. In: NOVAES, A. (Org.). O esquecimento da política. Rio de Janeiro: Agir, 2007.

SANTOS, W. G. Razóes da desordem. Rio de Janeiro: Rocco, 1993.

SANTOS, M. S. dos. Memória coletiva e teoria social. São Paulo: Annablume, 2003.

SOUZA, J. A construção social da subcidadania: para uma sociologia política da modernidade periférica. Belo Horizonte: Editora UFMG, 2006.

SPÓSITO, M. P. O povo vai à escola: a luta popular pela expansão do ensino público em São Paulo. São Paulo: Loyola, I984.

TELLES, V.S. Pobreza e cidadania. São Paulo: Editora 34, 200 I.

Recebido em Io abr. 2009 / aprovado em I4 maio. 2009.

\section{Para referenciar este texto}

CRUZ, J. A. da. O movimento social e a escola: da criação passada à invenção necessária. EccoS, São Paulo, v. II, n. I, p. 57-75, jan./jun. 2009. 
